\title{
The effect of vaccination on children's physical and cognitive development in the Philippines
}

\section{Citation}

Bloom, David E., David Canning, and Erica S. Shenoy. 2012. The effect of vaccination on children's physical and cognitive development in the Philippines. Applied Economics 44, no. 21: 2777-2783. doi:10.1080/00036846.2011.566203.

\section{Published Version}

doi:10.1080/00036846.2011.566203

\section{Permanent link}

http://nrs.harvard.edu/urn-3:HUL.InstRepos:33730172

\section{Terms of Use}

This article was downloaded from Harvard University's DASH repository, and is made available under the terms and conditions applicable to Other Posted Material, as set forth at http:// nrs.harvard.edu/urn-3:HUL.InstRepos:dash.current.terms-of-use\#LAA

\section{Share Your Story}

The Harvard community has made this article openly available.

Please share how this access benefits you. Submit a story.

\section{Accessibility}




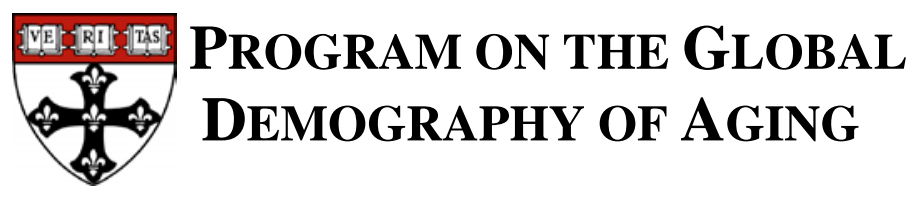

\author{
Working Paper Series
}

\title{
The Effect of Vaccination on Children's Physical and Cognitive Development in the Philippines
}

David E. Bloom, David Canning and Erica Seiguer

April 2011

PGDA Working Paper No. 69

http:// www.hsph.harvard.edu/pgda/ working.htm

The views expressed in this paper are those of the author(s) and not necessarily those of the Harvard Initiative for Global Health. The Program on the Global Demography of Aging receives funding from the National Institute on Aging, Grant No. 1P30 AG024409-06. 


\title{
The Effect of Vaccination on Children's \\ Physical and Cognitive Development in the Philippines
}

\author{
David E. Bloom, David Canning, and Erica Seiguer ${ }^{1}$ \\ Harvard School of Public Health
}

March 2010

\begin{abstract}
Summary
We use data from the Cebu Longitudinal Health and Nutrition Survey in the Philippines to link vaccination in the first two years of life with later physical and cognitive development in children. We use propensity score matching to estimate the causal effect of vaccination on child development. We find no effect of vaccination on later height or weight, but full childhood vaccination for measles, polio, TB, and DPT significantly increases cognitive test scores relative to matched children who received no vaccinations. The size of the effect is large, raising test scores, on average, by about half a standard deviation.
\end{abstract}

Corresponding author. E-mail: dcanning@hsph.harvard.edu

\footnotetext{
${ }^{1}$ The authors acknowledge financial support for this research received from the Global Alliance for Vaccines and Immunisation. They also received helpful comments from David Bishai on an earlier version of this paper.
} 


\section{Introduction}

The main rationale for childhood vaccination is that it reduces child mortality significantly and is a cost effective way to improve child health, particularly for poor households located in high-disease environments (e.g. Koenig, Bishai and Khan 2001, Breiman et al 2004, Brenzel et al 2006). Indeed, there is evidence that vaccination guards not only against a particular disease but also can provide a wide range of health benefits (Contreras 1989, Fonseca et al. 1996) making it a particularly valuable public health measure.

A secondary argument for the vaccination of children is that it can be thought of as an investment in human capital, with children’s health improvements resulting in their higher worker productivity and earnings as adults. The argument for viewing health interventions as techniques for promoting economic success and poverty reduction was set out in the report of the Commission on Macroeconomics and Health (World Health Organization 2001). Bloom, Canning, and Weston (2005) use estimates of the effect of vaccination on mortality rates, combined with estimates of the effect of life expectancy on productivity, to estimate that full immunization with six standard vaccines has a rate of return around $18 \%$ (about the same rate as primary education) as an investment in human capital, despite the long delay between childhood vaccination and entering work.

A weakness of the Bloom, Canning, and Weston approach is that it assumes that the productivity effect of mortality improvements due to vaccination is the same as for mortality improvements in general, and does not establish a direct mechanism linking vaccination to productivity. This paper investigates the link from vaccination to physical and cognitive development, and important part of the chain linking vaccination to economic outcomes. Improved physical and cognitive development have been linked to higher earnings among adults, 
allowing us to quantify the likely effect of vaccination on wages through these mechanisms. Studies show that ill health in childhood can be linked to lack of physical growth and low stature as an adult, which allows stature to be used as a marker for childhood health (Begum 1987, Stephensen 1999). Economic studies have linked the component of adult height associated with childhood nutrition and health to wages (Strauss and Thomas 1998, Savedoff and Schultz 2000, Schultz 2002, 2005). A second mechanism that may be important is the effect of ill health in childhood on school attendance and cognitive development (Sakti et al. 1999, Dickson et al. 2000). There is also strong evidence that the cognitive ability of teenagers in school persists into adulthood and is an important determinant of adult labor market success and earnings (Murnane, et al. 1995, Berkowitz 1998, Currie and Thomas 2001).

Existing studies have link vaccination to reductions in stunting and wasting in children up to age five (Adair and Guilkey 1997, Frongillo et al. 1997). We investigate whether this link persists by examining the link between height and weight at age 11 and immunization, but do not find a statistically significant relationship. However, we also look at the effect of childhood immunization on test scores that measure cognitive ability. We find a large and statistically significant impact of childhood vaccination on test scores. Cognitive ability, as measured by test scores, has in turn been linked to higher earnings in adults (Glewwe 1995, Moll 1998, Krueger 2005). Although it is not clear that the gains associated with higher cognitive skills in the wageearning sector in developing countries holds for the larger numbers of self-employed workers in the agricultural sector (Glewwe 2002) our results suggest that there may be a mechanisms through which early childhood vaccination can increase human capital and eventually worker productivity . 


\section{Data}

The Cebu Longitudinal Health and Nutrition Survey (CLHNS) is part of an ongoing longitudinal study of a cohort of Filipino women and the children they bore between 1 May 1983 and 30 April 1984. A single-stage cluster sampling procedure was used to randomly select 33 communities, or barangays (17 urban, 16 rural), from the Cebu metropolitan area. These barangays were completely canvassed in late 1982 and again in early 1983 to locate all pregnant women and to survey their households. Subsequent surveys took place immediately after birth and then every other month, for a period of two years. These bimonthly interviews allow us to track the immunization history of these children from birth to age two. We focus primarily on the 1994-5 follow-up study of women and children from the original CLHNS, begun in October 1994 and completed in October 1995. This follow-up provides anthropometric data on each child as well as scores on language, mathematics, and non-verbal reasoning tests. The children were around 11 years old at this follow-up.

We created a unique identifier for each child in the survey and merged data from the original CLHNS surveys from 1983-1986 with data from the 1994 follow-up survey, generating a sample of 1975 children. We dropped twins from the sample (26 cases), as well as observations that gave clearly erroneous information (22 cases) or who refused the interview (66 cases). there were 214 child deaths between the end of the original study and the 1994 follow up; the major cause of death was measles (34 children), but in many cases the cause of death is not known. ${ }^{2}$

We have data on six vaccines, measles, polio, tuberculosis (TB), diphtheria, pertussis, and tetanus. We consider vaccination status at age two years. For measles and TB vaccination, one dose of vaccine is required. For polio immunization, children should receive three doses of

\footnotetext{
${ }^{2}$ In this study, we concentrate on the benefits of vaccination conditional on survival to the follow-up survey, this allows our effects to be regarded as additional to the mortality reduction effects.
} 
vaccine by age two. Vaccination for diphtheria, pertussis, and tetanus uses a occurs together in a DPT vaccine. For DPT immunization, children should receive at least 3 doses in the first two year. Table 1 gives the numbers of vaccinations received by children as of 24 months. The levels of vaccination are quite low, despite twice-yearly mass campaigns for vaccination in the Philippines, expanded to four times a year in 1984.

In what follows, we compare the outcomes of children who received a the basic six vaccines (DPT, polio, measles, and TB) by age two with those who have had no vaccinations. We include in the treatment group children who had at least one vaccination of each of DPT, polio, measles, and TB. This gives us 85 fully vaccinated children compared with our control group of 1022 children who received no vaccinations at all. In principle, it would be possible to investigate the contribution of each vaccine separately, ${ }^{3}$ but it seems unlikely that a vaccine policy providing some, but not all, of these basic six would ever be considered given their known health benefits- indeed the current debate is about adding rotavirus and pneumococcal vaccines to the basic six being provided (Glass et al. 2005, Levine et al. 2006). We therefore estimate the productivity benefits of the vaccine package rather than the relative effectiveness of each of the basic vaccinations.

We use data on household characteristics taken during the initial study of the children at baseline. children's height and weight was measured in the 1994 follow-up survey. We construct BMI as weight divided by height squared. Data on test scores comes from tests administered as part of the 1994 follow up survey of the children. We use data on three tests. The first was a Philippines Non-Verbal Intelligence Test. In this test children were shown pictures of five culturally appropriate items of which four were similar in type, and one differed, and they were asked to identify which of the five was different. One hundred questions of this type were asked.

\footnotetext{
${ }^{3}$ Exploratory investigations along these lines revealed that measles vaccination was the most important for our result.
} 
The second test consisted of 60 mathematical questions while the third test consisted of 30 questions assessing reading ability in their native language. We standardize the each of the three test scores by taking the actual score measured in standard deviations from the mean.

\section{Methods}

Estimating the effect of vaccination on height, weight, and test scores is complicated by the fact that vaccination involves a choice by the child's parents. As a result, any difference between outcomes for vaccinated and non-vaccinated children may reflect family attributes associated with the decision to vaccinate rather than the effect of the vaccination itself. In a controlled experiment, a randomly selected set of children would be immunized while a control group would not be, and the difference between the outcome for the immunized group and the control group could be deemed a causal effect of immunization. In our study, however, the group that is immunized is not randomly selected; for example, we find immunization is more common for children with highly educated mothers. In this case, it is difficult to disentangle the effect of immunization and the effect of having a highly educated mother.

To try to overcome this problem, we use the propensity score matching method advocated by Rosenbaum and Rubin (1983). The key assumption in this approach is that conditional on observed household and child characteristics, treatment is random. This method matches each child (or group of children) who is immunized with a non-immunized child (or group of children) that has the same observed characteristics. To the extent that vaccination depends only on these observed characteristics, we can regard the children used as matches as controls for each vaccinated child. It follows that we can regard the difference in outcomes for treated and control children who are matched on all other observable characteristics as a causal 
effect. This approach has been used, for example, to determine whether piped water to homes reduces childhood diarrhea (Jalan and Ravallion 2003). Heckman and Navarro-Lozano (2004) and Imbens (2004) discuss the robustness of the matching approach and compare it to other methods of estimating causal effects of treatments that are not randomly assigned. Note that the rationale for the matching approach is very different from the rationale for the instrumental variable estimator that is often used in economics. We assume that once we match on all observable characteristics assignment to the treatment or control group is random. We can therefore simple compare average outcomes for treated children with matched controls; matching controls for any effect of covariates.

Exact matching of each immunized children to a control child is difficult when there are a large number of observable variables as it is difficult to find a match on every dimension simultaneously. Rosenbaum and Rubin (1983) show that rather than match on each characteristic it is sufficient to match on the "propensity score" - the probability that a child is immunized, given his or her characteristics. We find the propensity score by undertaking a probit analysis that estimates the probability of being fully immunized by age two (as opposed to having no vaccinations) depending on child and household characteristics. We then match children with the same propensity scores (rather than exactly the same characteristics) on the grounds that assignment to the treated or untreated group is random for children with the same propensity scores.

There is a further problem with this method in that propensity scores are a continuous variable and exact matches are unlikely. We instead construct approximate matches using four different mechanisms. The first, and simplest, method is to stratify the sample by propensity score (we use six strata) and to compare the treated with the untreated within each stratum. The 
second method is nearest-neighbor matching. This matches each immunized child with a control that is the un-immunized child with the nearest propensity score. Although reasonable, on occasion this leads to matches that are quite far apart in terms of propensity score. A third approach is to use radius matching, where each treatment is compared with controls whose propensity score lies within a given radius (we use a radius of 0.1 ) of the score of the treated child. Finally, we use a kernel estimator that allows matching over a wide radius but weights the matches, with more weight (we use a normal distribution as the kernel to generate weights) given to controls that are closer to the immunized child. This is a reasonable tradeoff, allowing more control observations to be used but not relying heavily on observations where the immunized children and their controls are very different in their propensity scores.

It is important to march vaccinated children with "control" children with the same observed individual and household characteristics. If the characteristics of a vaccinated child and the set of unvaccinated children do not overlap the effect of vaccination on the child is not identified, there are no reasonable matches between child and untreated individuals. To avoid this problem we take a common support restriction, using in the analysis only children in the a range of characteristics for which there are both vaccinated and unvaccinated children. This means that we should always have reasonably close matching children.

We estimate the average treatment effect in Stata as described in Becker and Ichino (2002). Given the relatively small numbers in our sample we use bootstrapped standard errors for all our estimators rather than analytic asymptotic standard errors.

We include in the matching observed factors that may be correlated with the take up of vaccination and may influence outcomes being observed. For example, Anderson et al. (1999) find that breast feeding affects cognitive development in a meta analysis of studies, while 
Daniels and Adair (2005) find that breast feeding influences cognitive development in our sample of children. It is therefore important to include breastfeeding as a potential confounding variable. Mendez and Adair (1999) link stunting in the early years of life to poor performance on the cognitive tests using the same data as here. We include birth weight of the child and height at two months to control for this effect. However, we do not include later progress in physical development as a matching variable because physical development may itself be a result of vaccination. Indeed, Adair and Gurkey (1997) shows that in this sample of children from the Philippines vaccination is linked to physical development in the first few years of life. For this study, it is important to include in the construction of the matched control group any variables that exist before vaccination and that may affect both the likelihood of being vaccinated and the outcome variables, but it is also important to exclude from the analysis any variables that occur afterwards and that may represent outcomes of the vaccination.

\section{Results}

Table 2 shows the results of a probit analysis to find the determinants of full vacciantion by age two. In this analysis we compare those with no vaccinations (vaccination dummy $=0$ ) with those that have all six vaccinations (vaccination dummy $=1$ ). The regression includes 33 village dummies whose coefficients are not reported (but are jointly significant) to control for community level differences in access to vaccination. The regression drops villages in which no children had any vaccinations (since there is no variation in the outcome), which leaves only 413 observations.

We find evidence of a positive association between vaccination and socioeconomic status, with children living in larger homes, and with private or public access to a toilet, fewer siblings, 
and better educated and better nourished mothers being more likely to be vaccinated. In addition, being vaccinated is positively associated with the number of days the child was breastfed. The only counterintuitive result among these variables is that children in homes with an electrical appliance (an iron) are less likely to have been vaccinated. We use the probability of being vaccinated given by the regression in table 2 as the propensity score for that child.

Table 3 reports results of comparing the test scores and physical development of vaccinated children against a matched control group consisting of children who are not vaccinated but have similar observed individual and household characteristics. Only observations from the range of propensity scores where we observe both immunized and non-immunized children are used. This "common support restriction" promotes the comparability of the treatment and control groups. This, however, means we lose a number of observations -treated individuals with very high propensity scores and potential controls with very low propensity scores- leaving 68 treated and 178 potential controls in the sample. The stratification method and the kernel estimator naturally use all these available controls. The nearest neighbor match uses a small number of controls with some controls matched to several treated children, while the radius used in the radius matching method is large enough to ensure that all potential controls are employed in at least one match.

The results are very similar over the four matching methods. In every case we find a significant effect of vaccination on all three cognitive test scores, either at the $5 \%$ or $1 \%$ significance level. However, we do not find a significant effect on either height or body mass index. We measure the test score effects in standard deviations to allow comparison with other studies. The effects found are fairly large, indicating a gain in test scores of around 0.5 standard 
deviations, a gain that would move the median student, at the 50th percentile, into the top 31\% of students.

\section{Conclusion}

Childhood vaccination has previously been linked to reduced morbidity and reductions in stunting and wasting in young children. Our results suggest that childhood vaccination has positive health effects that persist and are demonstrated in young teenagers in the form of increased cognitive ability. Since increased cognitive ability has in turn been linked to higher productivity and earnings as an adult our study opens the possibility of seeing childhood vaccination as an investment in human capital.

While our results are statistically significant, the sample size is relatively small due to the restriction of the sample to the common support. In addition the matching of treatment and control groups may be imperfect if there are unobserved confounding factors that affect both vaccination and cognitive development. We therefore do not see our results as definitive. However, the results do however highlight the potential significance of vaccination as a human capital investment and suggest that further research in this area is warranted. 
Table 1

Number of Vaccinations at Age 24 Months

\begin{tabular}{|c|c|c|c|c|}
\hline & None & 1 & 2 & 3 \\
\hline DPT & 1,106 & 400 & 208 & 108 \\
\hline Polio & 1,080 & 399 & 223 & 131 \\
\hline TB & 1,195 & 621 & & \\
\hline Measles & 1,656 & 106 & & \\
\hline
\end{tabular}

Note: 1,975 observations. Mothers were asked about their child's vaccination history over the last two months at two-month intervals. Vaccinations are cumulative for the 12 surveys. Any children with missing observations or with "don't know" responses for that vaccination for any of the 12 interviews are excluded. 


\section{Table 2}

\section{Probit Analysis of the Determinants of Vaccination}

$\begin{array}{ll}\text { Sex Dummy (Male=1) } & -0.296 \\ & (0.220) \\ \text { Birthdate (days) } & -0.0018 \\ & (0.0011) \\ \text { Duration Breast Fed (days) } & 0.0017^{* *} \\ & (0.0005) \\ & 0.107 \\ \text { Height at } 2 \text { months (cm) } & (0.057) \\ & -0.509 \\ \text { Birth Weight (kg) } & (0.306) \\ & 0.025 \\ \text { Mother's Height at Baseline (cm) } & (0.025) \\ & 0.039^{*} \\ \text { Mother's Weight at Baseline (kg) } & (0.019) \\ & 0.254^{* *} \\ \text { Number of rooms in the home } & (0.070) \\ & -0.835^{*} \\ \text { Electrical Appliance in the home } & (0.354) \\ \text { (owns electrical iron) } & 0.590 \\ \text { Water Supply in the home } & (0.307) \\ & 0.937^{*} \\ \text { Private Toilet in the home } & (0.373) \\ & 0.805^{*} \\ \text { Uses Public Toilet } & (0.362) \\ & -0.244^{* *} \\ \text { Number of Children in the home } & (0.074) \\ & 0.111^{* *} \\ \text { Mother's Education } & (0.037) \\ & -0.040 \\ \text { Spouse's Education } & (0.038) \\ & \\ \text { N } & 413 \\ \text { Pseudo R } & \\ & \\ & 0.433\end{array}$

Dependent Variable: Fully Vaccinated $=1$, No Vaccinations $=0$. Children in villages with no vaccinations dropped (perfect predictions). There are 85 children in the sample with all six vaccinations and 328 with no vaccinations in the remaining villages. Each regression contains 33 village dummies. Heteroskedasticity-consistent standard errors are reported in parentheses. * $(* *, * *)$ signifies significance at the $10 \%,(5 \%, 1 \%)$ level. 
Table 3

Effect of Vaccination on Child Outcomes

Mean difference between treatment and control groups

Using Propensity Scores to Construct Matched Control Groups

\begin{tabular}{|c|c|c|c|c|}
\hline & $\begin{array}{c}\text { Stratification } \\
\text { Matching } \\
\text { (six strata) }\end{array}$ & $\begin{array}{l}\text { Nearest- } \\
\text { Neighbor } \\
\text { Matching }\end{array}$ & $\begin{array}{c}\text { Radius } \\
\text { Matching } \\
\text { (radius 0.1) }\end{array}$ & $\begin{array}{l}\text { Kernel Matching } \\
\text { (Gaussian) }\end{array}$ \\
\hline $\begin{array}{l}\text { Verbal Reasoning } \\
\text { Test Score }\end{array}$ & $\begin{array}{c}0.508 * * \\
(0.177)\end{array}$ & $\begin{array}{c}0.451 * * \\
(0.174)\end{array}$ & $\begin{array}{c}0.553 * * \\
(0.153)\end{array}$ & $\begin{array}{c}0.434 * * \\
(0.150)\end{array}$ \\
\hline Math Test Score & $\begin{array}{l}0.510^{*} \\
(0.204)\end{array}$ & $\begin{array}{l}0.625 * * \\
(0.239)\end{array}$ & $\begin{array}{l}0.420 * * \\
(0.160)\end{array}$ & $\begin{array}{l}0.473^{*} \\
(0.217)\end{array}$ \\
\hline Language Test Score & $\begin{array}{l}0.423 * \\
(0.208)\end{array}$ & $\begin{array}{l}0.570 * * \\
(0.201)\end{array}$ & $\begin{array}{l}0.440 * \\
(0.174)\end{array}$ & $\begin{array}{l}0.432 * \\
(0.187)\end{array}$ \\
\hline Height & $\begin{array}{l}-0.056 \\
(0.224)\end{array}$ & $\begin{array}{c}0.027 \\
(0.224)\end{array}$ & $\begin{array}{l}-0.011 \\
(0.155)\end{array}$ & $\begin{array}{c}0.014 \\
(0.192)\end{array}$ \\
\hline Body Mass Index & $\begin{array}{l}-0.872 \\
(0.538)\end{array}$ & $\begin{array}{l}-1.023 \\
(0.588)\end{array}$ & $\begin{array}{l}-0.152 \\
(0.356)\end{array}$ & $\begin{array}{l}-0.560 \\
(0.409)\end{array}$ \\
\hline Number of Treated & 68 & 68 & 68 & 68 \\
\hline Number of Controls & 176 & 38 & 176 & 176 \\
\hline
\end{tabular}

Test score effects are measured in standard deviations, height in centimeters. Treatment and control cases are limited to a common support. Bootstrapped standard errors are reported in parentheses. ${ }^{*}(*)$ indicates significance at the 5\% (1\%) level. 


\section{References}

Adair, L.S. and Guilkey, D.K. (1997) Age-specific determinants of stunting in Filipino children. Journal of Nutrition,127, 314-320.

Anderson, J.W., Johnstone, B.M., Remley, D.T. (1999) Breast-feeding and cognitive development: a meta-analysis. American Journal of Clinical Nutrition, 70, 525-535.

Becker, S.O. and Ichino, A. (2002) Estimation of average treatment effects based on propensity scores. The STATA Journal, 2, 358-377.

Begum, A. (1987) The influence of illnesses on the food intake of young children. International Journal of Epidemiology, 16, 445-50.

Berkowitz, R. (1998) One point on the LSAT: how much is it worth? Standardized tests as a determinant of earnings. American Economist, 42, 80-89.

Bloom, D.E., Canning, D., and Weston, M. (2005) The value of vaccination. World Economics, 6, 1-25.

Breiman, R., Streatfield, P., Phelan, M., Shifa, N., Rashid, M., and M.Yunus (2004) Effect of infant immunisation on childhood mortality in rural Bangladesh: analysis of health and demographic surveillance data. Lancet, 364, 2204-2211.

Brenzel, L., L. J. Wolfson, J. Fox-Rushby, M. Miller and N. A. Halsey (2006) VaccinePreventable Diseases. In: Disease Control Priorities in Developing Countries. D. T. Jamison, J. G. Breman, A. R. Meashamet et al (Eds.). New York, Oxford University Press: 389-412.

Contreras, G. (1989) Effect of the administration of oral poliovirus vaccine on infantile diarrhoea mortality. Vaccine, 7, 211-2.

Currie, J., and Thomas, D. (2001) Early test scores, socioeconomic status, school quality and future outcomes, Research in Labor Economics, 20, 103-132.

Daniels, M.C. and Adair, L.S. (2005) Breast-feeding influences cognitive development in Filipino children. Journal of Nutrition, 135, 2589-2595.

Dickson, R., Awasthi, S., Williamson, P., Demellweek, C., and Garner P. (2000) Effects of treatment for intestinal helminth infection on growth and cognitive performance in children: systematic review of randomised trials. British Medical Journal, 320, 1697-701.

Fonseca, W., Kirkwood, B.R., Victora, C.G., Fuchs, S.R., Flores, J.A., Misago, C. (1996) Risk factors for childhood pneumonia among the urban poor in Fortaleza, Brazil: a case--control study. Bulletin of the World Health Organization, 74, 199-208. 
Frongillo, E.A. Jr., de Onis, M., Hanson, K.M. (1997) Socioeconomic and demographic factors are associated with worldwide patterns of stunting and wasting of children. Journal of Nutrition, 27, 2302-9.

Glewwe, P. (1996) The relevance of standard estimates of rates of return to schooling for education policy: a critical assessment. Journal of Development Economics, 51: 267-290.

Glewwe, P. (2002) Schools and skills in developing countries: education policies and socioeconomic outcomes. Journal of Economic Literature, 40, 436-482.

Glass, R.I., Bresee, J.S., Turcios,R., Fischer, T.K., Parashar, U.D., and Steele, A. D. (2005) Rotavirus Vaccines: Targeting the Developing World. The Journal of Infectious Diseases, 192, S160-S166.

Heckman, J., Navarro-Lozano, S. (2004) Using matching, instrumental variables and control functions to estimate economic choice models. The Review of Economics and Statistics , 86, 3057.

Imbens, G.W. (2004) Nonparametric Estimation of Average Treatment Effects Under Exogeneity: A Review. The Review of Economics and Statistics, 86, 4-29.

Jalan, J., and Ravallion, M. (2003) Does piped water reduce diarrhea for children in rural India? Journal of Econometrics, 112, 153-173.

Koenig, M.A., Bishai, D., and Khan, M.A. (2001). Health interventions and health equity: the example of measles vaccination in Bangladesh. Population and Development Review, 27, 283302.

Krueger, A.B. (2003) Economic Considerations and Class Size. Economic Journal, 113, F34-63.

Levine, O., O'Brien, K., Knoll, M., Adegbola, R., Black, S., Cherian, T., Dagan, R., Goldblatt, D., Grange, A. and Greenwood, B. (2006) Pneumococcal vaccination in developing countries, The Lancet, 367, 1880-1882.

Mendez, M.E., and Adair, L.S. (1999) Severity and timing of stunting in infancy and performance on IQ and school achievement tests in late childhood. Journal of Nutrition , 129, 1555-1562.

Moll, P.G. (1998) Primary schooling, cognitive skills and wages in South Africa. Economica, 65, 263-84.

Murnane, R.J., Willett, J.B., and Levy, F. (1995) The growing importance of cognitive skills in wage determination. The Review of Economics and Statistics , 77, 251-266.

Rosenbaum, P., and Rubin, D. (1983) The central role of the propensity score in observational studies for causal effects. Biometrika, 70, 41-55. 
Sakti, H., Nokes, C., Hertanto, W., Hendratno, S., Hall, A., and Bundy, D.A.P. (1999) Evidence for an association between hookworm infection and cognitive function in Indonesian school children. Tropical Medicine \& International Health, 4, 322-334

Savedoff, W.D. and Schultz, T.P. (2000) Wealth from health, Washington, DC: Inter-American Development Bank.

Schultz, T. P. (2005) Productive Benefits of Improving Health: Evidence from Low-Income Countries.” in Guillem López-Casasnovas, Berta Rivera and Luis Currais, eds., Health and Economic Growth: Findings and Policy Implications, Cambridge, Mass: MIT Press, 257-286.

Schultz, T.P. (2002) Wage gains associated with height as a form of human capital. American Economic Review, 92: 349-353.

Stephensen, C.B. (1999) Burden of infection on growth failure. Journal of Nutrition, 129, 534S538S.

Strauss, J., and Thomas, D. (1998) Health, nutrition and economic development. Journal of Economic Literature, 36, 766-817.

World Health Organization. Macroeconomics and Health: Investing in Health for Economic Development. Commission on Macroeconomics and Health, Geneva: World Health Organization, 2001. 